\title{
Study on the Parameters' Acquisition Method of Distributed Hydrological Model Based on RS
}

\author{
Jinping Sun ${ }^{1,2}$, Yong Liang ${ }^{1}$, Qin Yan ${ }^{1,2}$, and Chengming Zhang ${ }^{1}$ \\ ${ }^{1}$ School of Information Science and Engineering, Shandong Agricultural University, \\ Taian, Shandong, 271018, China \\ ${ }^{2}$ Chinese Academy of Surveying and Mapping, Beijing 100039, China \\ Jinpingsun1224@163.com
}

\begin{abstract}
Parameters' acquisition is a key step for the distributed hydrological model when simulating a basin. Based on remote sensing technology, this article proposed a parameters acquisition method of distributed hydrological model. That is extracting the important ground objects' information from the images to obtain some parameters of the model. This article also used the hierarchical classification principle, and introduced the extraction method of several ground objects. At last, by means of TopModel, we simulated the Xueye Reservoir, Laiwu City in Shandong Province. The experiment shows that this method can effectively improve the accuracy of model simulation.
\end{abstract}

\section{Presentation of Questions}

Distributed hydrological model is a kind of hydrological model, the model's advantage is able to take into account vegetation, soil, topography and other factors' impact on the hydrological processes in the watershed, and the spatial differences that existent in these elements can more accurately reflect the actual movement of hydrological [1]. So this model has been widespread concern in actual production. However, parameters used in distributed hydrological model generally have physical meaning, using the usual means of obtaining these parameters is more difficult, it limits the application of distributed hydrological model. As the improvement of remote sensing technology, now we can easily access remote sensing image of high-resolution and high spectrum, obtaining the soil, vegetation, geomorphology, topography, land use and other information underlying surface based on remote sensing become an effective mean.

At present, there hasn't formulation of parameters' acquisition method on the distributed hydrological model, the parameters' acquisition only exists as necessary stage in the process of hydrological modeling. In the study of watershed distributed hydrological model based on spatial information technology, Ling Feng referred to the parameters' acquisition of distributed TOPMODEL, mainly obtained the ground cover and soil data. Based on remote sensing technology, this article studied the parameters' acquisition method distributed hydrological model. 


\section{TopModel}

TOPMODEL is short for Topography Based Hydrological MODEL. It is a terrainbased semi-distributed hydrological model, proposed by Beven and Kirky in 1979 . TOPModel uses terrain space as the main structure, use terrain information (topographic index $\ln (\alpha / \tan \beta)$ or Soil - topographic index $\ln (\alpha / \operatorname{Totan} \beta)$, $\alpha$ represents the drainage area of the unit contour length, $\tan \beta$ represents the ground slope, $\mathrm{T}$ represents the soil permeability coefficient) to describe flow trends, based on the role of gravity drainage runoff along the slope movement principle, to simulate the runoff process [2]. Since proposed, the model has been widely used.

\subsection{The Basic Structure of the Model}

TOPMODEL's calculation structure is shown in Figure 1, Model divide the watershed into vegetation root zone, unsaturated zone and saturated soil zone three levels. In the vertical direction, first, rain enter vegetation root zone through infiltration, some of the moisture that reach the region is lost through evapotranspiration, while the rest continue to filter down to reach the unsaturated soil zone; The moisture that reach the region first enter the saturated groundwater area at a certain rate, and then form soil midstream through lateral flow, and move in the form of soil midstream; If the water surface of saturated groundwater zone rise constantly, the stream that enter this part will show out the ground in the low-lying area, which will form the overland flow.

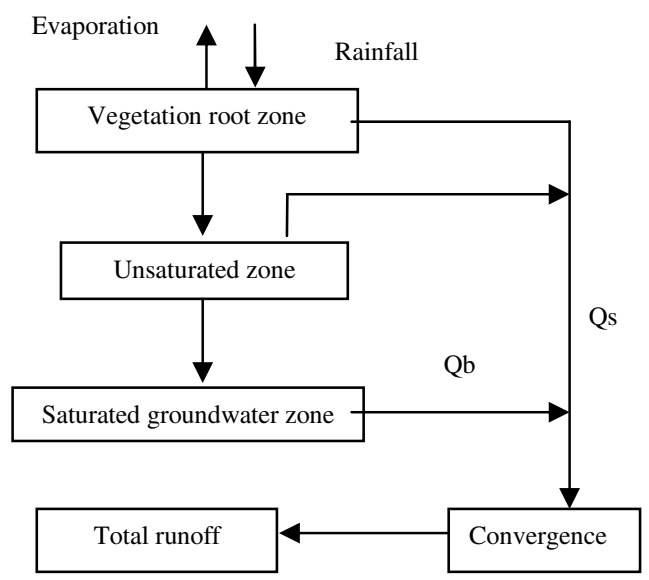

Fig. 1. Structure frame diagram of TOPMODEL

According to the production flow theory of TopModel, soil midstream $Q_{b}$ and saturated overland flow $Q_{s}$ together constitute the total runoff of watershed. The main calculation is as follows: 
(1) Calculation of evapotranspiration. The model believes that evapotranspiration only occurs in vegetation root zone, evaporation $E_{a}$ is calculated as:

$$
E_{a, i}=E_{p}\left(1-\frac{S_{r z, i}}{S_{r \max , i}}\right)
$$

In this formula, $S_{r z, i}$ is the volume of water shortage of vegetation root zone of point $\mathrm{i}$; $S_{r \max }$ is the biggest water capacity of root zone; $E_{p}$ is the evaporation capacity.

(2) Calculation of infiltration rate. The model believes that moisture of unsaturated zone finally enter the saturated zone at a certain rate, which mainly depends on soil structure and the current water storage situation. Equation (2.2) gives the calculation method of infiltration rate at point $i$ :

$$
q_{v, i}=\frac{S_{u z, i}}{S D_{i} t_{d}}
$$

In this formula: $q_{v, i}$ represents the infiltration rate at this point, $S_{u z, i}$ is the current Soil Moisture; $S D_{i}$ is the biggest storage capacity, in the actual calculation, $S D_{i}$ is always replaced by $z_{i}$, which is the depth between the groundwater and surface; $t_{d}$ is a time parameter.

(3) Calculation of saturated groundwater. Model first proposed three assumptions: interflow always in a steady state, that is, the rate of interflow is equal to the rate of the upstream; the hydraulic gradient of saturated groundwater is equal to surface local slope; soil hydraulic conductivity can be expressed by negative exponential function of saturated ground water zone's water depth, on this basis, use the following method to calculate the depth of surface water:

$$
Z_{i}=-S_{z m} \cdot \ln \left(\frac{\alpha_{i} \cdot R}{T_{0} \cdot \tan \beta_{i}}\right)
$$

(4) Saturation overland flow. Saturation overland flow will form when the depth between the saturated ground water and surface is negative, calculated as:

$$
Q_{s}=\frac{1}{\Delta t} \sum_{i} \max \left\{\left[S_{u s, i}-\max \left(z_{i}, 0\right)\right], o\right\} A_{i}
$$

$\Delta \mathrm{t}$ is the time step, $A_{i}$ is the effective runoff area.

(5) Interflow.

$$
Q_{b}=\int_{L} q_{i} d L
$$

(6) Confluence. Confluence's calculation contains confluence's calculation of slope and confluence's calculation of riverway, the delay time that associated with distance is used to calculate slope confluence, and a method that based on average 
flood wave velocity is used to calculate river confluence. Formula (5.6) is used to calculate the needed time from one point to the watershed's outlet:

$$
t=\sum_{i=1}^{N}\left[x_{i} /\left(v \bullet \tan \beta_{i}\right)\right]
$$

In the formula, $x_{i}$ is a length, Tan $\beta \mathrm{i}$ is the slope of $\mathrm{I}$ in the $\mathrm{N}$ section flow path, $\mathrm{v}$ is a speed parameter, as a constant. In the actual calculations, we can use a dimensionless distribution function curve that is similar to unit normal to calculate the output process of runoff, assume the runoff is equal in the entire watershed, and then divide the main channel into different levels for confluence.

\subsection{The Needed Parameters in TopModel's Calculation}

In TopModel, the main parameters used are in the following:

SZM: the parameter of index conduction function;

T0: when the soil reach saturated, T0 is the natural logarithm of soil effective conductivity;

Td: time parameter of gravity drainage;

SRmax: maximum water storage capacity of vegetation root zone;

SRinit: initial soil moisture initial value of vegetation root zone;

$\mathrm{RV}$ : the effective rate of surface overland flow;

ChVel: the effective rate of convergence of the main river.

\section{The Parameters' Acquisition Method of Hydrological Model Based on RS}

\subsection{The Data of MODIS and ETM}

MODIS is the main detector of EOS-AM1 satellite. It belongs to a kind of high spectral sensor, whose band is discontinue, (spectral range from 0.4 to 14.5 ), and ground resolution is very low (the resolution is $250 \mathrm{~m}, 500 \mathrm{~m}, 1000 \mathrm{~m}$ ). The resolution of ETM + data is very high, but the number of bands is small (only 8 bands). Table 1 gives the characteristics of each band.

Table 1. ETM data characteristics table

\begin{tabular}{|l|l|l|l|}
\hline Wave band & Type & Spectral range (um) & Ground resolution $(\mathbf{m})$ \\
\hline 1 & Blue-Green & $0.450-0.515$ & 30 \\
\hline 2 & Green & $0.525-0.605$ & 30 \\
\hline 3 & Red & $0.630-0.690$ & 30 \\
\hline 4 & Near IR & $0.775-0.900$ & 30 \\
\hline 5 & SWIR & $1.550-1.750$ & 30 \\
\hline 6 & LWIR & $10.40-12.50$ & 60 \\
\hline 7 & SWIR & $2.090-2.350$ & 30 \\
\hline 8 & Pan & $0.520-0.900$ & 15 \\
\hline
\end{tabular}




\subsection{The Technology of Image Fusion}

Image fusion is a process that the multiple remote sensing images according to certain algorithms, in the prescribed geographic coordinate system, generate a new image. Through data fusion, on the one hand, we can remove the useless information pertinently, eliminate redundancy, and reduce data processing dramatically to improve the efficiency of data processing; on the other hand, we can also gather the useful information in the massive multi-source data to facilitate all kinds of information facilitate all kinds of information, and exert respective strengths to get more useful information. In this study, the MODIS data and ETM + data was fused to make the experimental data to reach the purpose of simple and information complementary.

In this study, the fusion wavelet transform-based, main steps are as follows: suppose $\mathrm{A}, \mathrm{B}$ as the two original images, $\mathrm{F}$ is the fused image. First, transform each source image separately, to establish the small towers shape decomposition of the image; second, fuse each decomposition layer, different frequency components of each decomposition layer can be fused with different fusion operator, and finally get the fused wavelet pyramid; at last, carry out inverse wavelet transform on the fused wavelet pyramid (that is, the image reconstruction), the reconstructed image obtained is the fused image. Figure 2 is the fused image.

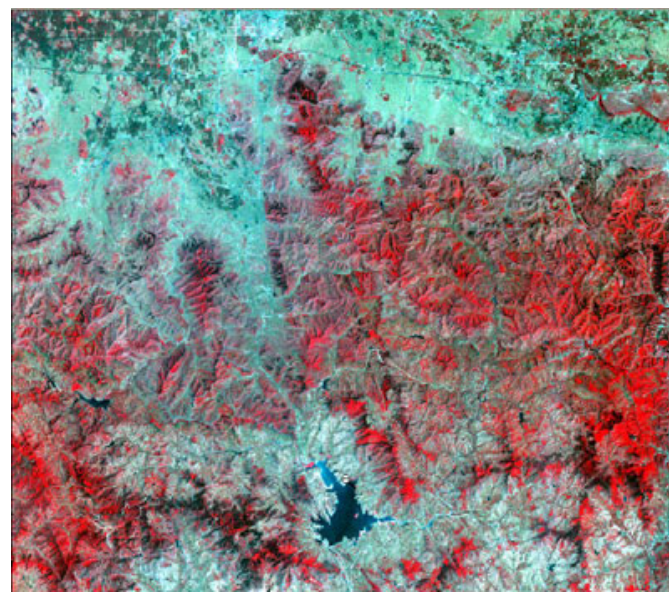

Fig. 2. The fused image

\subsection{Hierarchical Classification Structure}

In the application of multi-band remote sensing data, selecting a reasonable band combination or band operation to extract information is an important means to improve the classification accuracy and work efficiency. According to remote sensing Classification theory, each kind of ground objects can be characterized by spectral curve to show its unique internal features. In practice, due to a variety of sample imaging environment, makes the spectral information on images complex and changing. But for most remote sensing images, there are also several kinds of ground objects on a leading position, such as water, vegetation, rocks and soil. From the view of 
spectrum, these features of the ground objects can be characterized uniquely, the information that decides the basic types of images is always referred as a spectrum of information. Starting from the characteristics of remote sensing, we can use the Figure 3's hierarchical structure to express the classification information.

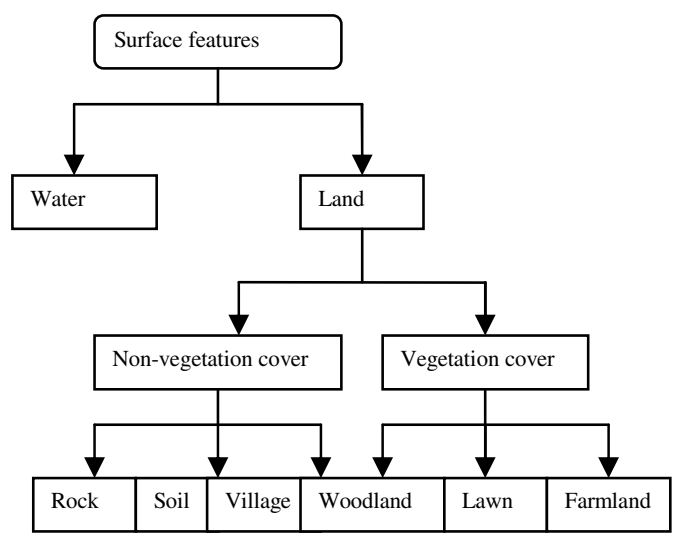

Fig. 3. The hierarchical classification chart

\subsection{The Feature Space of Water Body and the Main Background Ground Objects}

Water nearly absorbs all of the primary energy in the near infrared band, so the reflected energy in this band is very little, while plants and soil absorbed little energy in this band, so with a high reflectance characteristics. This makes water has significant difference between vegetation and soil in this band. In this band, the water shows dark tones, while the soil and vegetation is able to show relatively bright colors. However, when in the mountains, this might change because of the effect of the shadow of the mountain, for short infrared, the reflection in the shade is very low, which makes the shadow region in the image also has a clear dark tone, thereby makes it difficult to correctly distinguish water bodies and shadows.

Table 2. The spectrum brightness value of Water and the background ground objects

\begin{tabular}{|c|c|c|c|c|c|c|c|c|c|c|}
\hline & \multicolumn{2}{|l|}{ Band 2} & \multicolumn{2}{|l|}{ Band 3} & \multicolumn{2}{|l|}{ Band 4} & \multicolumn{2}{|l|}{ Band 5} & \multicolumn{2}{|l|}{ Band 7} \\
\hline & $\begin{array}{l}\text { Values of } \\
\text { samples }\end{array}$ & Mean & $\begin{array}{l}\text { Values of } \\
\text { samples }\end{array}$ & Mean & $\begin{array}{l}\text { Values of } \\
\text { samples }\end{array}$ & Mean & $\begin{array}{l}\text { Values of } \\
\text { samples }\end{array}$ & Mean & $\begin{array}{l}\text { Values of } \\
\text { samples }\end{array}$ & Mean \\
\hline Water & $\begin{array}{l}28,26,27, \\
30,34\end{array}$ & 29 & $3,0,0,9,14$ & 5 & $\begin{array}{l}13,12,12, \\
15,15\end{array}$ & 13 & $6,6,8,5,6$ & 6 & $5,1,2,1,3$ & 2 \\
\hline Woodland & $\begin{array}{l}24,26,30, \\
25,25\end{array}$ & 25 & $1,3,0,2,5$ & 2 & $\begin{array}{l}53,50,55, \\
59,49\end{array}$ & 53 & $\begin{array}{l}47,43,48, \\
56,49\end{array}$ & 49 & $\begin{array}{l}15,14,12, \\
15,18\end{array}$ & 15 \\
\hline village & $\begin{array}{l}31,32,29, \\
29,31 \\
\end{array}$ & 30 & $\begin{array}{l}14,17,14, \\
10,19\end{array}$ & 15 & $\begin{array}{l}28,31,30, \\
26,32\end{array}$ & 29 & $\begin{array}{l}30,41,58, \\
42,54 \\
\end{array}$ & 45 & $\begin{array}{l}17,24,32, \\
26,31\end{array}$ & 26 \\
\hline Farmland & $\begin{array}{l}39,36,36, \\
36,38,33\end{array}$ & 36 & $\begin{array}{l}41,32,37, \\
40,31\end{array}$ & 36 & $\begin{array}{l}59,54,49, \\
54,49 \\
\end{array}$ & 53 & $\begin{array}{l}105,84, \\
93,103,82 \\
\end{array}$ & 95 & $\begin{array}{l}57,43,47, \\
53,43 \\
\end{array}$ & 47 \\
\hline Shadow & $\begin{array}{l}21,21,22,2 \\
0,22\end{array}$ & 21 & $0,0,0,0,0$ & 0 & $\begin{array}{l}13,17,19, \\
17,20\end{array}$ & 17 & $\begin{array}{l}10,7,13, \\
9,11\end{array}$ & 10 & $2,2,4,3,4$ & 3 \\
\hline
\end{tabular}


In remote sensing images, we select typical pixels for water body and the background ground objects such as woodlands, residential areas, farmland and shadow, and statistic the spectrum brightness values, as shown in Table 2.

From the table we can see, in the band 2, water bodies can't easily distinguish with village and farmland; while easily distinguish with shadow and Woodland. In band 3 , the water and farmland has significantly difference, while has some confusion with Woodland and shadow. In band 4, the water body and other background ground objects all have obvious differences. In the band 5 and band 7, the water can distinguish with Woodland, village and farmland, but easily confused with shadow. According to sampling points of the same ground objects in the same wavelength, we can do the mean statistics, and make objects spectrum diagram, as is shown in Figure 4.

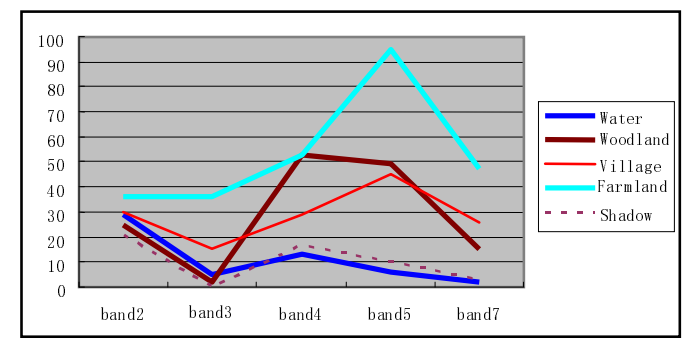

Fig. 4. Object Spectrum Chart

As we can see from the spectrum chart, the gray of water and shadow in the band 5 was significantly less than the band 2 , while other background objects are the opposite. In the band 2 and 3, the gray value of water is generally greater than the shadow's gray value. While in the band 4 and 5, the gray value of the shadow is generally greater than the water's gray value, add the two bands, you can increase the difference between water body and shadow. Add the band 2 and 3, add band 4 and 5, the enhanced spectrum chart is shown in Figure 5.

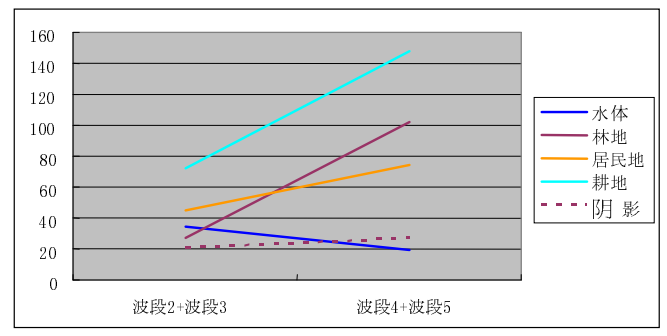

Fig. 5. The enhanced spectral chart

As we can see from the above chart, after the band combination, water and other background ground objects can distinguish more obviously. So, we can use the spectrum value of the combination of band $2+$ band 3 , band $4+$ band 5 to compose feature space to extract water, woodland, village, farmland and shadow. 


\subsection{Parameters' Acquisition}

Remote sensing data (aerial photographs and satellite images) can provide information on spatial characteristics of watershed, is the most feasible method to describe hydrological variability, especially in the absence of regional ground-based observations. In distributed hydrological modeling, the application of remote sensing data can be summarized as follows: used as the input data and parameter estimation of the model, there are seven specific areas: 1) rainfall intensity's observation and spatial pattern; 2) the calculation of evapotranspiration and soil moisture retrieval; 3) snow cover; 4) groundwater; 5) land cover and land use classification; 6) water feature; 7) vegetation parameter extraction [6].

For each basin, because the condition of underlying surface is different, when carries on the simulation of the basin, different basin's model parameter ought to be able to reflect under the pad surface condition spatial variation. However, in practice, in addition to the differences in the terrain can take advantage of each basin's terrain exponential distribution function, model parameters that reflect the vegetation, soil conditions can not are difficult to obtain through actual measurements, you can only use hydrologic data to rate parameters.

The biggest storage capacity of vegetation root area SRmax is a pattern parameter, soil parameters can obtain by referring to elated content of the AGWA [6] model. The parameters related to soil is soil saturated hydraulic conductivity $\mathrm{T}_{0}$ and soil hydraulic conductivity along with depth of soil change coefficient of attenuation $\mathrm{M}$, the soil saturated hydraulic conductivity determined according to the soil texture:

$$
\mathrm{T}_{0}=\mathrm{P}_{\text {clayey }} \times \mathrm{T}_{0 \text { clayey }}+\mathrm{P}_{\text {sand }} \times \mathrm{T}_{0 \text { sand }}+\mathrm{P}_{\text {silt }} \times \mathrm{T}_{0 \text { silt }}
$$

In the formula: $\mathrm{P}_{\text {clayey }}, \mathrm{P}_{\text {sand }}$ and $\mathrm{P}_{\text {sitt }}$ represent the percentage of clayey sand and silt in the soil, if the basin contains many kinds of different types the soils, then we can calculate by area weighted average of different soil types; $T_{\text {0calyey }}, T_{\text {osand }}$ and $T_{\text {0silt }}$ represent the saturated hydraulic conductivities of the three material, and need to rate through the actual material.

\section{Experimental Results and Discussion}

\subsection{Experimental Area and Data Source}

The experiment was carried out in the Xueye Reservoir, Laiwu City in Shandong Province. Xueye reservoir is one large reservoir of Shandong Province, controls the drainage area of 444 square kilometers, has a total capacity of 221 million cubic meters, has useful storage capacity of 112 million cubic meters, and dead storage of 2.8 million cubic meters. The location of Reservoir is very superior, and the materials are very rich, which provide a favorable condition for the experiment. Figure 6 is the position diagram of Xueye Reservoir. 


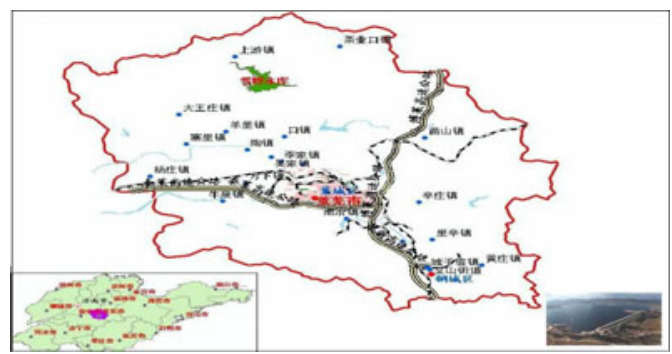

Fig. 6. The position diagram of Xueye Reservoir

MODIS data is downloaded from the Global land cover Fund web, the resolution is 30m, ETM + data is the image data including Xueye Reservoir Basin with eight-band.

\subsection{Watershed Simulation}

In order to verify the validity of the above parameters acquisition method, according to the extracted results, this article used TopModel and the actual data of Xueye Reservoir, carried out the simulation on Xueye Reservoir basin.

According to the classification rules of Chapter III, we extracted the fused image using the supervised classification methods in REDAS, and got the information of 6 kinds of ground objects. The result is as follows:

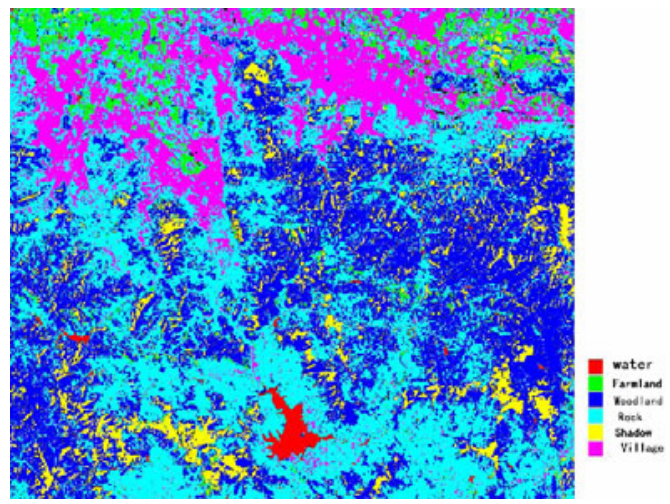

Fig. 7. Classification Results Chart

According to the results of classification to caculate model parameters.

Then we selected the eight years' flood from 2001 to 2008, and carried out the simulation. According to hydrological norms, we introduced the certainty factor DC, the relative runoff error Er, relative peak error of Eq, and peak time error $t$, these parameters are the evaluation indexes in a screening flood. The process of simulation is as shown from Figure 9 to Figure 15, table 3 gives the evaluation index. 


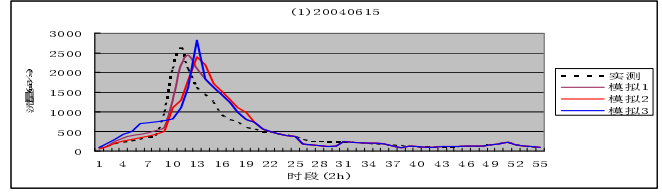

Fig. 8. The flood simulation situation of No. 20040615

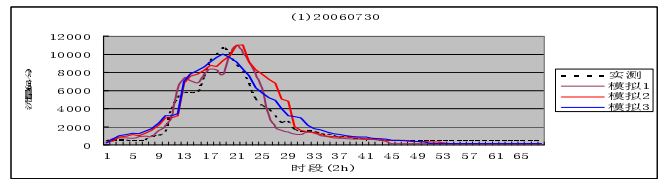

Fig. 9. The flood simulation situation of No. 20060730

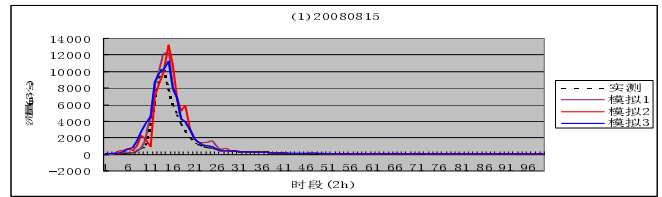

Fig. 10. The flood simulation situation of No. 20080815

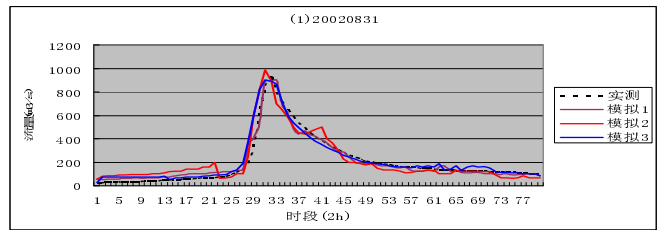

Fig. 11. The flood simulation situation of No. 20020831

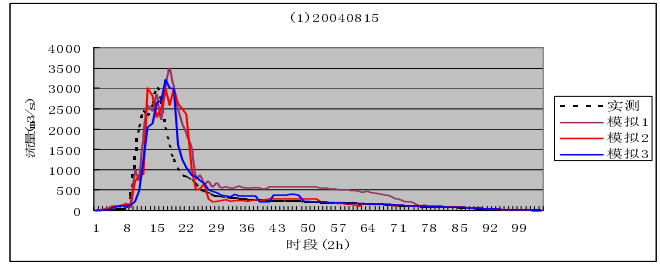

Fig. 12. The flood simulation situation of No. 20040815

From the simulation results we can see, besides the No. 20060730 flood, the uncertainty factor is all higher than 75\%, and besides the No. 20060729 flood the runoff error is all smaller than the required $20 \%$. The result reaches the B level, and we can say the method can be applied to practical production. 


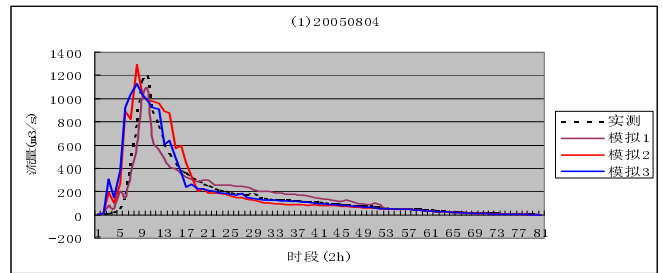

Fig. 13. The flood simulation situation of No. 20050804

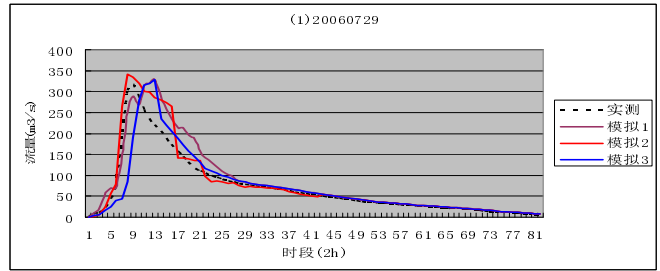

Fig. 14. The flood simulation situation of No. 20060729

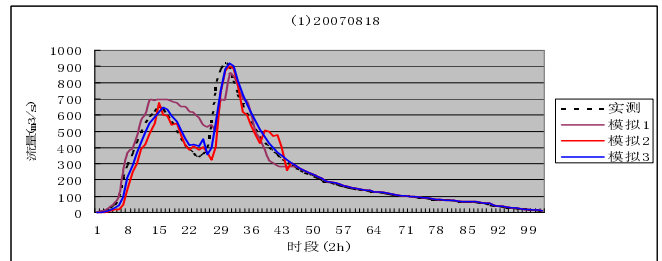

Fig. 15. The flood simulation situation of No. 20070818

Table 3. Parameter calibration case

\begin{tabular}{|l|l|l|l|l|}
\hline F1ood N0. & DC & $E_{R}(\%)$ & $E_{q}(\%)$ & $\tau(\%)$ \\
\hline 20040615 & 0.88 & 25.24 & 0.81 & 0 \\
\hline 20060730 & 0.67 & -26.32 & -33.37 & -1 \\
\hline 20080815 & 0.74 & 25.5 & -17.1 & 1 \\
\hline 20020831 & 0.71 & 28.51 & -20.75 & 1 \\
\hline 20040815 & 0.9 & -3 & -14.3 & 1 \\
\hline 20050804 & 0.93 & -9.31 & 1.91 & 0 \\
\hline 20060729 & 0.78 & -17.89 & -27.67 & 0 \\
\hline 20070818 & 0.78 & 36.47 & -10.91 & 1 \\
\hline Mean & 0.8 & 7.4 & -15.17 & \\
\hline
\end{tabular}




\section{Conclusions}

Based on the hierarchical classification principle, this article studied the classification problem of remote sensing images, and finally proposed a parameters' acquisition method of distributed hydrological model. The method is to extract information that is relevant to distributed hydrological model parameters from remote sensing images. Compared with traditional methods of parameter determination, the method that using RS to obtain hydrological model parameters is more convenient [3]. At last, this article used TOPMODEL to simulate Xueye Reservoir, the result shows that the method has some practical value.

\section{References}

[1] Liu, Z., Li, L., Zhu, C.: Comparison Research of Two Distributed Hydrologic Models in Flood Forecasting. Water Resources and Power 24(2), 70-73 (2006)

[2] Cheng, J., He, S.: Research on TOPMODEL in Basin Flood Forecasting. Henan Water Resources \& South-to-North Water Diversion 12(2) (2008)

[3] Kang, M.S., Park, S.W., Lee, J.J., Yoo, K.H.: Applying SWAT for TMDL programs to a small watershed containing rice paddy fields. Agricultural Water Management 79(1), 72 $92(2006)$

[4] Ju, W., Gao, P., Wang, J., Zhou, Y., Zhang, X.: Combining an ecological model with remote sensing and GIS techniques to monitor soil water content of croplands with a monsoon climate. Agricultural Water Management 97(8), 1221-1231 (2010)

[5] Shukla, A., Arora, M.K., Gupta, R.P.: Synergistic approach for mapping debris-covered glaciers using optical-thermal remote sensing data with inputs from geomorphometric parameters. Remote Sensing of Environment 114(7), 1378-1387 (2010)

[6] Yu, X.-j., Sun, J.-d., Zhang, S.-t., Shi, F.-x.: The Development, Situation and Future of Distributed Hydrological Model. Shanxi Hydrotechnics 2 (May 2009) (Total No.172) 